\title{
COMPARATIVE EVALUATION OF POSTOPERATIVE ANALGESIC EFFECTS OF WOUND INFILTRATION WITH TRAMADOL, LEVOBUPIVACAINE AND COMBINATION OF THE TWO IN CHILDREN UNDERGOING INGUINAL HERNIA AND UNDESCENDED TESTIS SURGERY
}

\author{
Aftab Ahmad Khan', Khaleel Ahmad Najar2, Mushtaq Ahmad Rather33, Basharat Saleem ${ }^{4}$ \\ ${ }^{1}$ Associate Professor, Department of Anaesthesiology and Critical Care, Government Medical College, Srinagar. \\ 2PG Scholar, Department of Anaesthesiology and Critical Care, Government Medical College, Srinagar. \\ 3 Senior Resident, Department of Anaesthesiology and Critical Care, Government Medical College, Srinagar. \\ 4 Professor \& HOD, Department of Anaesthesiology and Critical Care, Government Medical College, Srinagar.
}

\section{ABSTRACT}

\section{BACKGROUND}

Wound infiltration with local anaesthetics may improve postoperative analgesia and has become increasingly common. It has the ability to reduce the need for opioids, additional complications, duration of hospital stay and its provision of effective postoperative analgesia. Tramadol infiltration of wound has been shown to have effects similar to those of local anaesthetics.

\section{AIMS AND OBJECTIVES}

To investigate the effects of wound infiltration with levobupivacaine and tramadol on postoperative analgesia in children undergoing elective unilateral inguinal hernia and undescended testis surgery.

\section{METHODS}

Ninety children (Age Group 1 to 7 years) who were scheduled to undergo elective unilateral inguinal hernia and undescended testis surgery were included in the study. Patients were allocated to 3 groups of 30 each: Group A received wound infiltration with $2 \mathrm{mg} / \mathrm{kg}$ Tramadol in $0.2 \mathrm{~mL} / \mathrm{kg}$ saline, Group B received wound infiltration with $0.2 \mathrm{~mL} / \mathrm{kg}$ of $0.25 \%$ Levobupivacaine and Group C received wound infiltration with $2 \mathrm{mg} / \mathrm{kg}$ Tramadol plus $0.25 \%$ Levobupivacaine (total volume of solution as $0.2 \mathrm{~mL} / \mathrm{kg}$ ). Pain score was assessed using FACES pain scale at 1, 4, 8, 12 and 24 hours postoperatively. Patients with pain score of $\geq 4$ were treated with paracetamol suppository ( $20 \mathrm{mg} / \mathrm{kg}$ body weight) as rescue analgesia. Respiratory rate and pulse rate were also recorded at $1,4,8$, 12 and 24 hours postoperatively. The frequency of side effects and rescue analgesic used were also recorded during the 24-hour postoperative period.

\section{RESULTS}

Average pain scores, respiratory rate and pulse rate were lowest in Group C compared to Group A and Group B at 1, 4, 8, 12 and 24 hours postoperatively ( $\mathrm{P}$ value of $<0.05$ ). Average analgesic requirement among the three groups showed a statistically significant difference ( $\mathrm{P}$ value of $<0.05$ ) and time to first analgesic requirement was longer in Group C compared to Group A and Group B. However, the incidence of side effects among the three groups was statistically insignificant ( $\mathrm{P}$ value of $>0.05$ ).

\section{CONCLUSION}

Infiltration of the wound site with combined Levobupivacaine and Tramadol provides significantly better analgesia compared with Levobupivacaine or Tramadol alone.

\section{KEYWORDS}

Tramadol, Levobupivacaine, Inguinal Hernia, Undescended Testis, Analgesia.

HOW TO CITE THIS ARTICLE: Khan AA, Najar KA, Rather MA, et al. Comparative evaluation of postoperative analgesic effects of wound infiltration with tramadol, levobupivacaine and combination of the two in children undergoing inguinal hernia and undescended testis surgery. J. Evolution Med. Dent. Sci. 2016;5(30):1559-1563, DOI: 10.14260/jemds/2016/367

\section{INTRODUCTION}

The international association for the study of pain defines pain as an "Unpleasant sensory and emotional experience associated with actual or potential tissue damage or described in terms of such damage. ${ }^{\prime \prime}$ Children being special in this regard, as it is a very complex phenomenon in them. It is also very difficult to differentiate restlessness or crying due to pain from that of hunger or fear in the children.

Financial or Other, Competing Interest: None.

Submission 20-02-2016, Peer Review 16-03-2016,

Acceptance 23-03-2016, Published 14-04-2016.

Corresponding Author:

Dr. Mushtaq Ahmad Rather,

Senior Resident,

Department of Anaesthesiology and Critical Care,

GMC, Srinagar-190006.

E-mail: mushtaqahmad767@gmail.com

DOI: $10.14260 /$ jemds/2016/367
An effective pain therapy to block or modify the myriad physiologic responses to stress has become an essential component of modern paediatric anaesthesia and surgical practice. Historically, children have been undertreated for pain and for painful procedures because of the wrong notion that they neither suffer or feel pain nor respond to or remember the painful experiences to the same degree as adult do. An unproved safety and efficacy of the analgesics and worries about the risk of opioid-induced respiratory depression, added more reasons for the undertreatment of pain in children.

Popular dogma had suggested that the human child does not feel pain and that it is dangerous to give him powerful analgesia because of the risk of addiction. ${ }^{2}$ undertreatment of post-operative pain even in the children and newborns may trigger biochemical and physiologic stress response and cause impairments in pulmonary, cardiovascular, neuro-endocrinal, gastrointestinal, immunological and metabolic functions. ${ }^{3}$ 
Finely et al. have recently reported that many types of the so called "Minor" surgeries can cause significant pain in children and that parents have a number of misconceptions concerning pain treatment. ${ }^{4}$ In spite of all these reports, the postoperative pain in paediatric patient is not adequately managed despite of its cause of morbidity and even some reported mortality. 5

\section{MATERIAL AND METHODS}

After obtaining approval from Hospital Ethical Committee and informed written consent from the parents/guardian of the children, the study was undertaken in Government SMHS Hospital, Srinagar. This was a prospective, hospital-based study; 90 children (Age group of 1 to 7 years) scheduled to undergo elective unilateral inguinal herniotomy and undescended testis surgery and belonging to American society of anaesthesiologists [ASA-1 and II] category were selected for this study.

\section{Exclusion Criteria}

- Patients allergic to any of the study drugs, either levobupivacaine or tramadol.

- Patients with known neurological, neuromuscular or psychiatric diseases.

- Patients with known clotting disorders.

Patients selected for the study were admitted at least 24 hours prior to surgery. Pre-anaesthetic checkup was done at that stage. A thorough history including history of any comorbid disease, pre-anaesthetic exposure, medication intake and allergy to any drug was also elicited.

General physical examination as well as systemic examination of cardiovascular system, respiratory system and central nervous system was performed. Airway assessment was done to predict the airway status of the patient. Minimum basic investigations were advised. The patients were advised to remain fasting as per standard fasting criteria for paediatric patients prior to surgery.

Patients were randomly assigned to three groups as below, in whom wound infiltration was done at the end of surgery.

1. Group A: Patients received wound infiltration with 2 $\mathrm{mg} / \mathrm{kg}$ of tramadol $(0.2 \mathrm{~mL} / \mathrm{kg})$.

2. Group B: Patients received wound infiltration with $0.25 \%$ levobupivacaine $(0.2 \mathrm{~mL} / \mathrm{kg})$.

3. Group C: Patients received wound infiltration with 2 $\mathrm{mg} / \mathrm{kg}$ Tramadol plus $0.25 \%$ Levobupivacaine $(0.2$ $\mathrm{mL} / \mathrm{kg}$ ).

Preoperative baseline Heart Rate, Blood Pressure and SPO2 were recorded by connecting the patient to multichannel monitor. Intravenous access established with 22-G I/V cannula. All patients were premedicated with injection fentanyl (1 $\mu \mathrm{g} / \mathrm{kg}$ body wt.) and General Anaesthesia was induced with injection thiopentone sodium (4-5 mg/kg body wt.). Inj. Atracurium ( $0.5 \mathrm{mg} / \mathrm{kg}$ body wt.) as muscle relaxant and LMA of appropriate size was placed. Anaesthesia was maintained with halothane (0.2-0.6\%) in a mixture of $50 \%$ and $50 \% \mathrm{~N} 20 / 02$ and patients ventilated to normocapnia.

Standard intraoperative monitoring included ECG, NIBP, HR, Etco 2 and SPO2. Ringers lactate infusions were used for replacement and maintenance as per standard guidelines of fluid replacements. At the end of surgery, just before skin closure, infiltration of the surgical wound was performed by the surgeon in all the patients.

Residual neuromuscular block was reversed and LMA was removed. Patients were shifted to PACU for assessment of pain scores and other vital parameters. Children were discharged from PACU to surgical ward when they achieved a modified Aldrete score. 6 of 9 .

Pain was assessed using FACES pain scale. Pain scores were recorded at 1, 4, 8, 12 and 24 hours postoperatively. Patients with pain score of $\geq 4$ received paracetamol $(20 \mathrm{mg} / \mathrm{kg}$ body wt.) suppository per rectally. Other parameters like pulse rate and respiratory rate were also recorded at similar intervals. The incidence of nausea/vomiting, pruritus, local allergic reaction and rescue analgesic requirement was also recorded.

\section{Statistical Analysis}

Age, weight, duration of surgery, average pain scores and total analgesic requirements were compared using ANOVA (One way analysis of variance). All data were collected and comparison between groups was expressed as arithmetic mean and standard deviation (mean \pm SD) and analysed using standard statistical tests and inferences were drawn accordingly.

\section{RESULTS}

In our study, there was no statistically significant difference regarding the demographic profile of patients.

\begin{tabular}{|c|c|c|c|c|}
\hline $\begin{array}{c}\text { Variabl } \\
\text { e }\end{array}$ & $\begin{array}{c}\text { Group A } \\
(\mathbf{n = 3 0 )}\end{array}$ & $\begin{array}{c}\text { Group B } \\
(\mathbf{n = 3 0 )}\end{array}$ & $\begin{array}{c}\text { Group C } \\
(\mathbf{n = 3 0 )}\end{array}$ & $\begin{array}{c}\text { P- } \\
\text { value }\end{array}$ \\
\hline $\begin{array}{c}\text { Age } \\
\text { (years) }\end{array}$ & $3.48 \pm 1.32$ & $3.27 \pm 1.19$ & $3.53 \pm 0.99$ & $\begin{array}{c}0.646 \\
\#\end{array}$ \\
\hline $\begin{array}{c}\text { Weight } \\
\text { (Kg) }\end{array}$ & $\begin{array}{c}16.17 \pm 3.1 \\
2\end{array}$ & $\begin{array}{c}16.43 \pm 2.9 \\
6\end{array}$ & $\begin{array}{c}16.27 \pm 2.7 \\
3\end{array}$ & $\begin{array}{c}0.939 \\
\#\end{array}$ \\
\hline $\begin{array}{c}\text { Duratio } \\
\text { n Of } \\
\text { Surgery }\end{array}$ & $\begin{array}{c}48.67 \pm 3.4 \\
3\end{array}$ & $\begin{array}{c}48.67 \pm 3.8 \\
9\end{array}$ & $\begin{array}{c}48.87 \pm 4.4 \\
1\end{array}$ & $\begin{array}{c}0.599 \\
\#\end{array}$ \\
\hline \multicolumn{4}{|c|}{ Table 1: Demographic Profile of Patients } \\
\hline
\end{tabular}

Patients in Group C had lower pulse rates (p value of 0.001) and respiratory rates ( $p$ value of 0.001 ) than in Group A and Group B throughout the postoperative period as shown in Figure 1 and 2 .

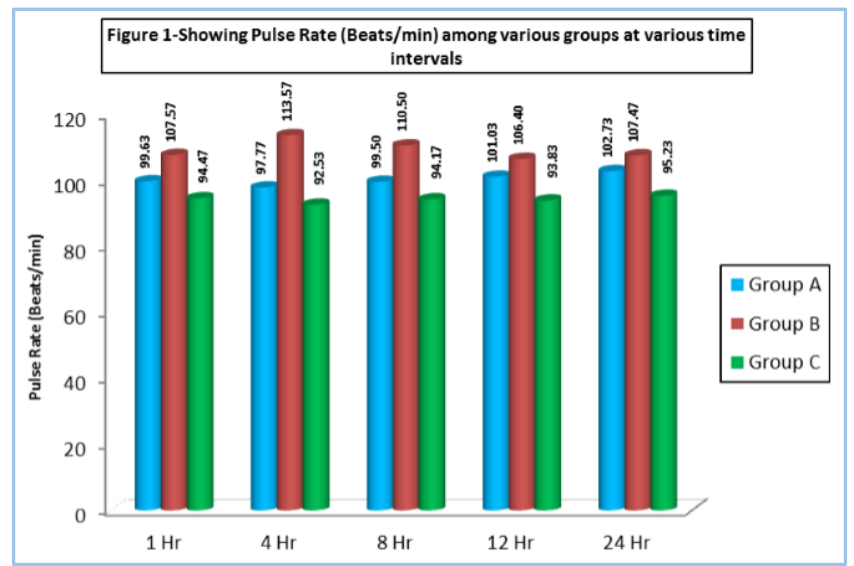



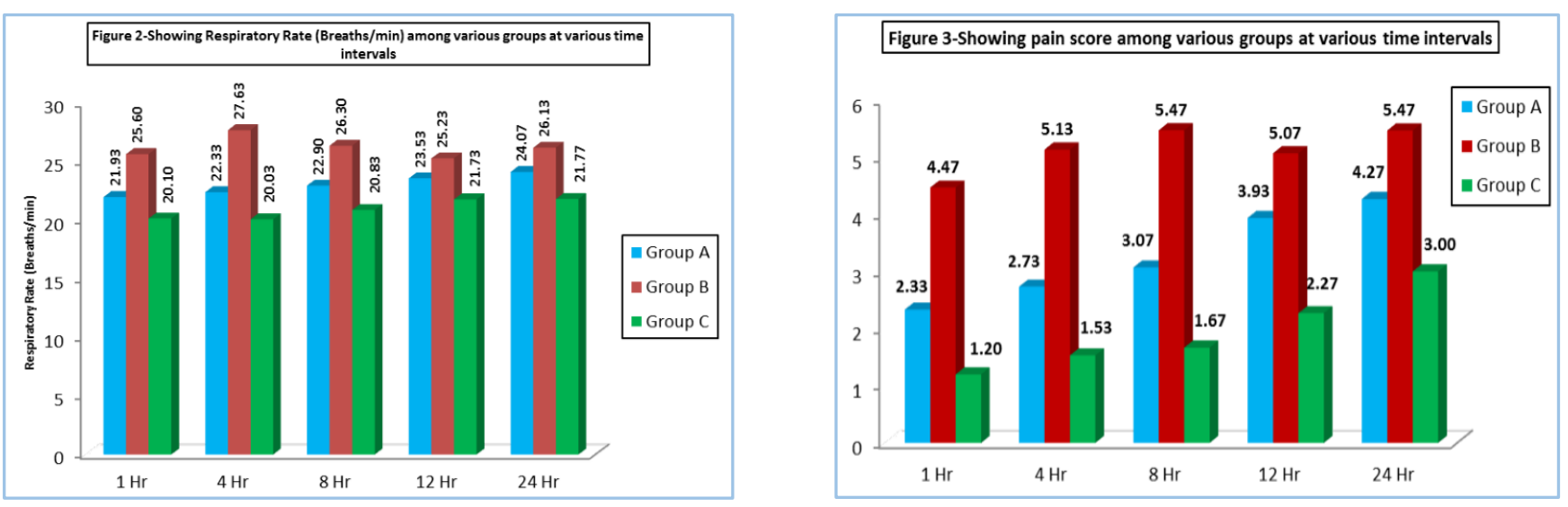

When the groups were compared with respect to postoperative VAS values (Fig. 3), significant differences were detected at hours $1(\mathrm{P}<0.001)$ (Group C vs. Group A, P=0.013; Group B, $\mathrm{P}<0.001$; Group A vs. B, $\mathrm{P}<0.001 ; 4(\mathrm{P}<0.001)$ (Group C vs. Group A $\mathrm{P}=0.005$; Group C vs. Group B, $\mathrm{P}<0.001$; and Group B vs. Group A, $\mathrm{P}<0.001 ; 8$ ( $\mathrm{P}<0.001)$ (Group C vs. Group A, $\mathrm{P}=0.002$; Group C vs. Group B, P<0.001; Group B vs. Group A, $\mathrm{P}<0.001$ ); 12 ( $\mathrm{P}<0.001$ ) (Group C vs. Group A, P=0.001; Group C vs. Group B, P<0.001; Group B vs. Group A, $\mathrm{P}=0.021$ ) and $24(\mathrm{P}<0.001$ ) (Group C vs. Group A, $\mathrm{P}=0.012$; Group C vs. Group $\mathrm{B}, \mathrm{P}<0.001$; Group B vs. Group A, $\mathrm{P}=0.017)$.

\begin{tabular}{|c|c|c|c|c|c|c|c|}
\hline Time & $\begin{array}{c}\text { Group } \\
\text { A }\end{array}$ & $\begin{array}{c}\text { Group } \\
\text { B }\end{array}$ & $\begin{array}{c}\text { Group } \\
\text { C }\end{array}$ & $\begin{array}{c}\text { A vs. B } \\
\text { P value }\end{array}$ & $\begin{array}{c}\text { A vs. C } \\
\text { P value }\end{array}$ & $\begin{array}{c}\text { B vs. C } \\
\text { P value }\end{array}$ & $\begin{array}{c}\text { Overall p } \\
\text { value }\end{array}$ \\
\hline $1 \mathrm{hr}$. & $2.33 \pm 1.69$ & $4.47 \pm 1.87$ & $1.20 \pm 1.35$ & $<0.001^{*}$ & $0.013^{*}$ & $<0.001^{*}$ & $<0.001^{*}$ \\
\hline $4 \mathrm{hr}$. & $2.73 \pm 1.70$ & $5.13 \pm 1.54$ & $1.53 \pm 1.46$ & $<0.001^{*}$ & $0.005^{*}$ & $<0.001^{*}$ & $<0.001^{*}$ \\
\hline $8 \mathrm{hr}$. & $3.07 \pm 2.02$ & $5.47 \pm 1.74$ & $1.67 \pm 1.30$ & $<0.001^{*}$ & $0.002^{*}$ & $<0.001^{*}$ & $<0.001^{*}$ \\
\hline $12 \mathrm{hr}$. & $3.93 \pm 1.93$ & $5.07 \pm 1.72$ & $2.27 \pm 1.95$ & $0.021^{*}$ & $0.001^{*}$ & $<0.001^{*}$ & $<0.001^{*}$ \\
\hline $24 \mathrm{hr}$. & $4.27 \pm 2.09$ & $5.47 \pm 1.96$ & $3.00 \pm 1.64$ & $0.017^{*}$ & $0.012^{*}$ & $<0.001^{*}$ & $<0.001^{*}$ \\
\hline \multicolumn{7}{|c|}{ Table 2: Comparison of Pain Score at different time intervals } \\
\hline
\end{tabular}

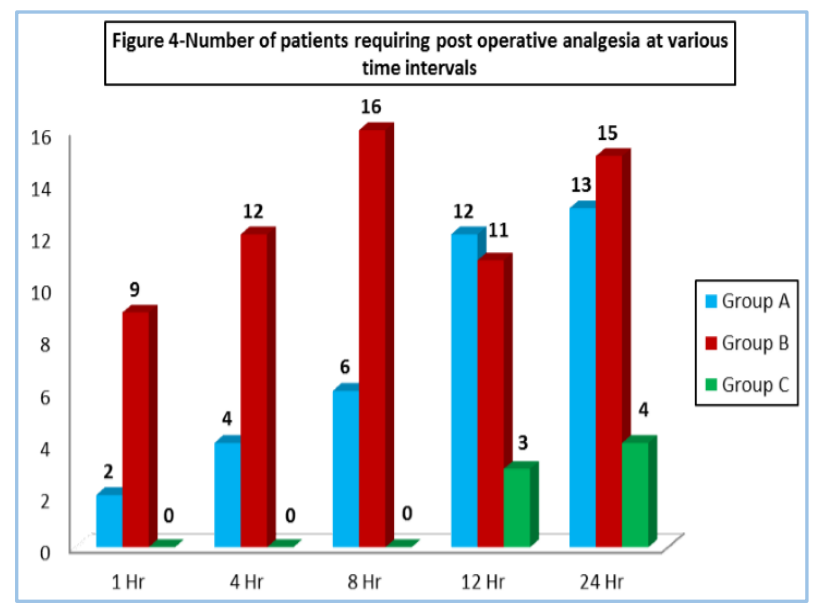

Post-operative rescue analgesia in the form of paracetamol suppository ( $20 \mathrm{mg} / \mathrm{kg}$ body weight) was given to children when the pain score was $\geq 4$ in the first 24 hours. In Group C, none of the patients required rescue analgesia in the 1st, 4th and 8th hour post-operatively. Only $3(10 \%)$ received rescue analgesia in the 12 th hour and $4(13.3 \%)$ in the 24 th hour post-operatively.

In Group A rescue analgesia was required in $2(6.6 \%)$ of patients in the 1 st hour, $4(13.3 \%)$ in the $4^{\text {th }}$ hour, $6(20 \%)$ in the $8^{\text {th }}$ hour, $12(40 \%)$ in the $12^{\text {th }}$ hour and $13(43.3 \%)$ in the $24^{\text {th }}$ hour post-operatively. In Group B $9(30 \%)$ of patients received rescue analgesia in the 1 st hour, $12(40 \%)$ in the $4^{\text {th }}$ hour, $16(53.3 \%)$ in the $8^{\text {th }}$ hour, $11(36.6 \%)$ in the $12^{\text {th }}$ hour and $15(50 \%)$ in the $24^{\text {th }}$ hour post-operatively.

\begin{tabular}{|c|c|c|c|c|c|c|c|}
\hline \multirow{2}{*}{$\begin{array}{c}\text { Time } \\
\text { Interval }\end{array}$} & \multirow{2}{*}{$\begin{array}{c}\text { Group } \\
\text { A }\end{array}$} & \multirow{2}{*}{$\begin{array}{c}\text { Group } \\
\text { B }\end{array}$} & \multirow{2}{*}{$\begin{array}{c}\text { Group } \\
\text { C }\end{array}$} & \multirow{2}{*}{$\begin{array}{c}\text { P-value } \\
\text { (Overall) }\end{array}$} & \multicolumn{3}{|c|}{ P-value (Intergroup) } \\
\hline & & & & & A vs. B & A vs. C & B vs. C \\
\hline $1 \mathrm{hr}$. & $2(6.6)$ & $9(30)$ & $0(0)$ & $0.001^{*}$ & $0.045^{*}$ & 0.492 & $0.002^{*}$ \\
\hline $4 \mathrm{hr}$. & $4(13.3)$ & $12(40)$ & $0(0)$ & $<0.001^{*}$ & $0.041^{*}$ & 0.112 & $<0.001^{*}$ \\
\hline $8 \mathrm{hr}$. & $6(20)$ & $16(53.3)$ & $0(0)$ & $<0.001^{*}$ & $0.007 *$ & $0.024 *$ & $<0.001^{*}$ \\
\hline $12 \mathrm{hr}$. & $12(40)$ & $11(36.7)$ & $3(10)$ & $0.019 *$ & 0.791 & $0.017^{*}$ & $0.033^{*}$ \\
\hline $24 \mathrm{hr}$. & $13(43.3)$ & $15(50.0$ & $4(13.3)$ & $0.007^{*}$ & 0.605 & $0.022^{*}$ & $0.006^{*}$ \\
\hline
\end{tabular}

Requirement of rescue analgesia (Paracetamol suppository $20 \mathrm{mg} / \mathrm{kg}$ body weight) in the first 24 hours postoperatively was lowest in Group C $(0.3 \pm 0.45)$ as compared to Group A (1.3 \pm 0.74$)$ and Group B $(2.1 \pm 0.71)$. Intergroup comparison between $\mathrm{A}$ and $\mathrm{C}, \mathrm{B}$ and $\mathrm{C}$ and $\mathrm{A}$ and $\mathrm{B}$ revealed $\mathrm{a}$ statistically significant difference (P value of $<0.001$ ).
The incidence of side effects among the three groups was statistically insignificant. Seven patients in Group A, four patients in Group B and only one patient in Group C had postoperative nausea and vomiting (0.075). 
None of the patients in Group A, B or C had any local reaction ( $\mathrm{P}$ value of 1.000).

\section{DISCUSSION}

The reduction in postoperative pain using infiltration with local anaesthetics over wound edges was reported by Copelle in $1935 .{ }^{7}$ with local infiltration or infiltration in the pain sensitive plains, afferent impulses from the site of incision and injury are reduced. This reduces the sensitization and consequent hyperalgesia. The risks associated with the parenteral administration of analgesics and central neuraxial block are avoided. Simplicity and safety are the hallmarks of the technique.

Local anaesthetic agents commonly used for surgical wound infiltration include lidocaine, prilocaine, bupivacaine, ropivacaine and levobupivacaine. 8,9 Opioids have been shown to have local anaesthetic effects in animal and clinical studies.10,11 Tramadol is a synthetic analogue of codeine, which acts through both opioid and non-opioid mechanisms of action. ${ }^{12}$ Tramadol may be used as a local anaesthetic agent for minor surgeries; similarly, it may be used as an adjuvant to local anaesthetics. ${ }^{12}$ The analgesic effects of tramadol seem to have 3 different mechanisms: agonism in weak $u$ opioid receptors; prevention of reuptake of noradrenaline and hydroxytryptamine (5-HT) neurotransmitters in descending inhibition pain pathways and providing 5-HT release.10,13 Wound infiltration with tramadol provides 2 additional hours of analgesia compared with intramuscular use. ${ }^{14}$

In our present study, patients in Group $\mathrm{C}$ had lowest postoperative pain scores at 1, 4, 8, 12 and 24 hours postoperatively compared to Group A and Group B. Overall, mean postoperative pain scores were $3.00 \pm 1.6$ in Group C, $4.27 \pm 2.0$ in Group A and $5.47 \pm 1.9$ in Group B with a statistically significant difference (P value of $<0.001$ ). Similar trends were followed by respiratory rate and pulse rate at different time intervals. Mean respiratory rate and pulse rate in Group C were lowest at 1, 4, 8, 12 and 24 hours postoperatively compared to Group A and Group B with a statistically significant difference at all time intervals $(\mathrm{P}<0.001)$.

Similar results were obtained in one of the previous studies done by Ozyilmaz K, (2012) Rescue analgesia (Paracetamol $20 \mathrm{mg} / \mathrm{kg}$ body wt. suppository) was supplemented whenever the pain score was $\geq 4$. When the groups were analysed with respect to the need for rescue analgesia requirement within 24 hours postoperatively, none of the patients in Group $\mathrm{C}$ required rescue analgesia up to the $8^{\text {th }}$ postoperative hour. Only three patients in Group C required rescue analgesia in the $12^{\text {th }}$ hour and another four in the $24^{\text {th }}$ hour. However, intergroup comparison of rescue analgesic consumption between Group A and Group C were statistically insignificant at 1 and 4 hours postoperatively ( $P$ value $>0.05$ ); 9 patients in Group B required rescue analgesia during the first hour in comparison to 2 patients in Group A. Intergroup comparison of rescue analgesia between Group A and B revealed a statistically insignificant difference $(p>0.05)$ after the $8^{\text {th }}$ postoperative hour.

Similar results were obtained by Ozyilmaz et al. (2012). Within the 24-hour postoperative period, only one patient in Group $C$ had nausea and vomiting in comparison to 7 patients in Group A and 4 in Group B. However, the difference was statistically insignificant ( $p>0.05$ ). None of the patients in any study groups had any local reaction. $(\mathrm{p}>0.05)$.

Similar results were obtained by Ozyilmaz K, (2012) who showed that combination of tramadol and levobupivacaine reduced the incidence of side effects compared to the rest of the groups.

\section{SUMMARY AND CONCLUSION}

During the 24-hour postoperative period after elective inguinal herniotomy and orchidopexy, the combination of Tramadol and Levobupivacaine provided superior analgesia with lowest pain scores and reduced rescue analgesic consumption and side effects.

Wound infiltration with tramadol alone provided better postoperative analgesia than levobupivacaine alone. However, the incidence of side effects was higher in tramadol alone group.

\section{Limitations of the study}

Since pain is a subjective phenomenon with wide variability of responses among the individuals, it is difficult to standardize the variable. Pain that may be tolerable for one person may be intolerable for another person. It may be difficult to assess and grade the pain thus producing lot of unwanted bias in the study.

\section{REFERENCES}

1. Mersky H. Pain terms: a list with definitions and notes on usage recommended by the IASP subcommittee on taxonomy. Pain 1979;6(3):249-52.

2. Aynsley Green A. Pain and stress in infancy and childhood where to now? Paediatr Anaesth 1996;6(3):167-72.

3. Rawal N, Sjostrand U, Christofferson E, et al. Comparison of intramuscular and epidural morphine for postoperative analgesia in the grossly obese: influence on postoperative ambulation and pulmonary function. Anaesth Analg 1984;63(6):583-92.

4. Finley GA, McGranth PJ, Forward SP, et al. Parents management of children pain following 'minor' surgery. Pain 1996;64(1):83-7.

5. Fisher SM. Postoperative pain management in paediatrics. Br J Perioper Nurs 2000;10(2):80-4.

6. Loach A, editor. The management of postoperative pain. In: orthopaedicanaesthesia edward arnold London, 1994;2nd ed.

7. Aldrete JA. The post-anesthesia recovery score revisited. J Clin Anesth 1995;7(1):89-91.

8. Ford GT, Guenter CA. Toward prevention of postoperative pulmonary complications. Am Rev Respir Dis 1984;130(1):4-5.

9. Ozyilmaz K, Ayoglu H, Okyay RD, et al. Postoperative analgesic effects of wound infiltration with tramadol and levobupivacaine in lumbar disk surgeries. J Neurosurg Anesthesiol 2012;24(4):331-5.

10. Mert T, Gunes Y, Guven M, et al. Comparison of nerve conduction blocks by an opioid and a local anaesthetic. Eur J Pharmacology 2002;439(1-3):77-81.

11. Jaffe RA, Rowe MA. A comparison of the local anesthetic effects of meperidine, fentanyl, and sufentanil on dorsal root axons. Anesth Analg 1996;83(4):776-81. 
12. Yurtlu S, Hanci V, Kargi E, et al. The analgesic effect of dexketoprofen when added to lidocaine for intravenous regional anaesthesia: a prospective, randomized, placebocontrolled study. J Int Med Res 2011;39(5):1923-31.

13. Matsota P, Papageorgiou-Brousta M, Kostopanagiotou G. Wound infiltration with levobupivacaine: an alternative method of postoperative pain relief after inguinal hernia repair in children. Eur J Pediatr Surg 2007;17(4):270-4.
14. Altunkaya H, Ozer Y, Kargi E, et al. The postoperative analgesic effect of tramadol when used as subcutaneous local anesthetic. Anesth Analg 2004;99(5):1461-4. 